\title{
The period Gene Encodes a Predominantly Nuclear Protein in Adult Drosophila
}

\author{
Xin Liu,, ${ }^{1,2, a}$ Laurence J. Zwiebel, ${ }^{1,2, b}$ David Hinton, ${ }^{3, c}$ Seymour Benzer, ${ }^{3}$ Jeffrey C. Hall, ${ }^{2}$ and Michael Rosbash ${ }^{1,2}$ \\ ${ }^{1}$ Howard Hughes Medical Institute and ${ }^{2}$ Department of Biology, Brandeis University, Waltham, Massachusetts 02254 and \\ ${ }^{3}$ Division of Biology, California Institute of Technology, Pasadena, California 91125
}

\begin{abstract}
The period gene of Drosophila melanogaster (per) is important for the generation and maintenance of biological rhythms. Previous light microscopic observations indicated that per is expressed in a variety of tissues and cell types and suggested that the perprotein (PER) may be present in different subcellular compartments. To understand how PER influences circadian rhythms, it is important to define its subcellular location, especially in adult flies where inducible promoter experiments suggested that it is most relevant to circadian locomotor activity rhythms. To this end, we report the results of an immunoelectron microscopic analysis of wild-type flies and per- $\beta$-galactosidase ( $\beta$-gal) fusion gene transgenics using a polyclonal anti-PER antibody or an anti$\beta$-gal antibody, respectively. Most of the PER antigen and the fusion gene product were located within nuclei, suggesting that PER acts in that subcellular compartment to affect circadian rhythms. The results are discussed in terms of per's possible biochemical functions.
\end{abstract}

Circadian rhythms are ubiquitous in eukaryotic organisms. Among genes known to influence circadian rhythms, the period gene of Drosophila melanogaster (per) is one of the best studied (Hall and Rosbash, 1988; Rosbash and Hall, 1989; Young et al., 1989). Point mutations within the per coding region either abolish rhythmicity $\left(\right.$ per $\left.^{01}\right)$, or lengthen [per $\left.{ }^{\mathrm{L}}(29 \mathrm{hr})\right]$ or shorten [pers (19 hr)] circadian periods (Konopka and Benzer, 1971; Baylies et al., 1987; Yu et al., 1987). Conceptual translation of cDNAs indicated a major product of about 1200 amino acids (Jackson et al., 1986; Citri et al., 1987). As relatives with a clearly defined biochemical function were not identified in data base searches, the nucleic acid analysis did not reveal how per might act to influence biological rhythms.

\footnotetext{
Received Aug. 27, 1991; revised Feb. 11, 1992; accepted Feb. 14, 1992.

We are grateful to U. Banerjee and R. Young for help with the initial immunoelectron microscopic experiments at Caltech, to N. O'Donoghue for help with electron microscopy at Brandeis, and to $\mathrm{H}$. Steller for instruction on the silver enhancement. We appreciate that S. Crews and O. Hankinson communicated results prior to publication. We thank $\mathrm{H}$. V. Colot for comments on the manuscript and $T$. Tishman for secretarial assistance. This work was supported by an NIH grant (GM-33205) to J.C.H. and M.R., and by the NSF (DMB-8908154) and the Gordon Ross Foundation (S.B.)

Correspondence should be addressed to Michael Rosbash, Department of Biology, Brandeis University, Waltham, MA 02254.

a Present address: Whitehead Institute, MIT, 9 Cambridge Center, Cambridge, MA 02142.

b Present address: Department of Cell and Developmental Biology, Harvard University, 16 Divinity Avenue, Cambridge, MA 02138.

c Present address: Department of Pathology, University of California School of Medicine, 2011 Zonal, Los Angeles, CA 90033.

Copyright (C) 1992 Society for Neuroscience $0270-6474 / 92 / 122735-10 \$ 05.00 / 0$
}

Developmental studies have shown that per's expression is temporally and spatially controlled (James et al., 1986; Liu et al., 1988; Saez and Young, 1988; Siwicki et al., 1988). Products were identified in mid/late embryos, third instar larvae, mid/ late pupae, and adults. In embryos, they were localized to the brain and ventral ganglia (e.g., James et al., 1986). In embryos as well as third instar larvae, PER has also been localized to salivary glands (Bargiello et al., 1987). In pupae, per expression was detected first in the brain and ring gland, and then in a variety of neural and non-neural tissues. This widespread expression pattern lasts from late pupae throughout adulthood. per-expressing neural tissues include the compound eye, optic lobes, central brain, and thoracic ganglia. per-expressing nonneural tissues include the gut, Malpighian tubules, and ovaries.

It is not known why per is expressed in so many tissues, as transplantation and mosaic experiments have indicated that per's expression in the head is where this gene influences locomotor activity rhythms (Handler and Konopka, 1979; Konopka et al., 1983). The role that per expression might play during development is also unknown. Heat-shock promotercontrolled activation of this gene during various stages of the life cycle suggested that per expression in adults is necessary and sufficient for circadian rhythms of locomotor activity (Ewer et al., 1988, 1990).

Determining the subcellular location of the per protein might shed light on a possible biochemical function. However, the results from this approach have not been consistent. By conventional light microscopic analysis, the subcellular locations of the per protein (PER) in adult tissues have been describcd as apparently nuclear, perinuclear, and cytoplasmic (Liu et al., 1988; Saez and Young, 1988; Siwicki et al., 1988). In addition, Bargiello et al. (1987) assigned PER to the cell boundary regions of third instar larval salivary glands. These results were interpreted in the context of the strong effects of per mutations on intercellular communication measured in these gland cells. This interpretation was extended to include a model for per's mode of action and its effect on oscillator function within the adult brain: PFR might also act at cell boundaries in this tissue to influence gap junction-mediated communications that could be part of the clock (Bargiello et al., 1987).

Because this model was developed from studies of non-neural tissues at a relatively early stage of the Drosophila life cycle, and because of the complex nature of PER's apparent subcellular locations and the low resolution of the light microscopic analyses, we carried out an immuno-EM analysis of adult fly tissues, concentrating on the ganglia within the fly's head. One type of EM analysis was developed for a per- $\beta$-gal fusion transformant 
(Liu et al., 1988) and used an anti- $\beta$-gal antibody. With a new anti-PER polyclonal antibody, we then extended the analysis to wild-type flies. For most of the tissues examined, we obtained consistent results that defined the nucleus as the primary compartment for PER localization. The data suggest that PER exercises its influence on circadian rhythms as a nuclear protein.

\section{Materials and Methods}

Antibody production. Bacterial-mediated per expression for the generation of rat polyclonal serum was carried out by incorporating all but the N-terminal 110 amino acids of PER into the plasmid vector pAR3038 (Rosenberg et al., 1986). This plasmid was prepared by ligating a 3.6 kilobase BglII fragment from pCDA (Citri et al., 1987) directly into the BamHI site of pAR3038, resulting in the synthesis of a fusion protein containing the first 14 amino acids of the $T 7$ phage coat protein and the C-tcrminal 1108 amino acids of PER. This plasmid (pAR3038 per) was transformed into the Escherichia coli strain BL21(DE3) pLys (Studier and Moffatt, 1986) by standard methods. Transformed cells were grown at $37^{\circ} \mathrm{C}$ to an $\mathrm{OD}_{600}$ of $1.0 \mathrm{in} \mathrm{L-broth} \mathrm{with} 100 \mu \mathrm{g} / \mathrm{ml}$ ampicillin and $25 \mu \mathrm{g} / \mathrm{ml}$ chloramphenicol. Expression of bacterial PER was induced by addition of isopropyl $\beta$-D-thiogalactopyranoside (IPTG) to the culture medium at a final concentration of $0.4 \mathrm{~mm}$, after which cells were incubated for $2 \mathrm{hr}$ at $37^{\circ} \mathrm{C}$. Expression was assayed by SDS-PAGE and Western blotting (data not shown).

The $E$. coli PER fusion protein (Eco-PER) was purified by SDSPAGE. The protein band was excised from preparative gels and used to immunize female Sprague-Dawley rats (Charles River Laboratories) after emulsification in Freund's complete adjuvant (GIBCO-Bethesda Research Labs). All immunizations were by intraperitoneal injection using standard procedures (Harlow and Lanc, 1988). Rats werc boostcd with additional material emulsified with Freund's incomplete adjuvant (GIBCO-Bethesda Research Labs) at 3 week intervals; sera collection began 6 weeks after the initial immunization and continued thereafter at 2 week intervals. Sera were diluted over a $6 \log$ range and assayed for PER-specific immunoreactivity by ELISA. Briefly, microtiter plates were coated with $20 \mu \mathrm{g} / \mathrm{ml}$ of bacterial protein extracts made either from pAR3038 per-containing cells induced with IPTG or from control cells containing only the pAR3038 vector. Immunoreactive response was measured by absorbance at $\mathrm{OD}_{490}$ and adjusted for nonspecific background.

Affinity purification was performed by initially clearing the sera of non-IgG proteins by affinity chromatography on a protein $G$-silica gel column (GENEX) according to the manufacturer's instructions. The IgG fraction was further purified, first by passing it through an Affi-Gẹl 10 (Bio-Rad) resin coupled to a control moth cell (Sf9) protein extract that was PER negative. This flow through fraction was then applied to a second Affi-Gel resin coupled to an Sf9 moth cell protein extract containing recombinant per-baculovirus-directed PER protein (baculoper, a kind gift of Dr. J. Rutila). After extensive washing, anti-PER antibodies were eluted with $100 \mathrm{~mm}$ glycine, $\mathrm{pH} 2.5$, followed by 100 mM triethanolamine, $\mathrm{pH} 12.5$, directly into $1.5 \mathrm{M}$ Tris, $\mathrm{pH} 7.5$, and then dialyzed against Tris-buffered saline overnight at $4^{\circ} \mathrm{C}$. The final product was concentrated by ultrafiltration with Centricon microconcentrators (Amicon), and BSA was added to a final concentration of $0.1 \mathrm{mg} / \mathrm{ml}$.

Electron microscopy. For the wild-type fly tissues stained with antiPER antibody, flies from a Canton-S strain were entrained in a $12 \mathrm{hr}$ light $/ 12 \mathrm{hr}$ dark cycle for $3 \mathrm{~d}$ and collected on the fourth day just before lights on on the fourth day so that the protein would be at its peak level (cf. Zerr et al., 1990). The early stages of the immunohistochemical procedures were as previously developed for the whole-mount $\beta$-gal staining of adult heads (Liu et al., 1991). It is important to follow the methods carefully (and those described below, specifically for the EM aspects of these localization studies); the nature of the reagents, incubation times, and so on, had to be calibrated by trial and error, because no immuno-EM procedures have (to our knowledge) been reported for "en bloc" fixation/staining of Drosophila brain tissues. The later stages for these procedures departed from the whole mount staining described in Liu et al. (1991) in two ways. First, the primary antibody was the Eco-PER antibody described above. Second, the diaminobenzidine reaction time was substantially increased and was followed by a prolonged silver enhancement treatment (Liposits et al., 1984), until credible brain signals appeared in the electron microscope (both about 10-20 min). Mutant per ${ }^{11}$ tissues were processed in parallel for each set of experiments. The treated specimens were postfixed with $2 \%$ glutaraldehyde in PBS (pII 7.4) and $1 \%$ osmium in phosphate buffer $(0.1 \mathrm{M}$ sodium phosphate, $\mathrm{pH} 7.4$ ), sequentially, for $1 \mathrm{hr}$ each at room temperature. These tissues were rinsed three times with phosphate buffer between the two fixations and rinsed three times with double-distilled water after the fixations; each rinse lasted for $10 \mathrm{~min}$. Fixed tissues were stained with $0.5 \%$ uranyl acetate, $3 \%$ sucrose, $24 \mathrm{~mm}$ sodium hydroxide overnight at $4^{\circ} \mathrm{C}$ and then rinsed with phosphate buffer three times $(10 \mathrm{~min}$ each). The uranyl acetate-treated tissues were dehydrated with an ethanol series $(30 \%, 50 \%, 70 \%, 85 \%$, and $95 \%, 10$ min each; $100 \%, 10$ min twice). The dehydration was continued with $100 \%$ propylene oxide treatment twice $(10 \mathrm{~min}$ each). The dehydrated tissues were embedded in EMbed 812 (Electron Microscopy Sciences). Thin sections (80-100 $\mathrm{nm}$ ) were cut and analyzed in a transmission electron microscope (RCA or Philips 301). For experiments without immunotreatment, fly heads were dissected as previously described (Liu et al., 1991) and put through the fixation and sectioning treatment described above.

For the per- $\beta$-gal fusion gene transgenic strain, tissues were stained with anti- $\beta$-gal antibody (Cappel). Flies were not entrained because they were arrhythmic due to their per ${ }^{11}$ genetic background (cf. Liu et al., 1988). The treatment of these tissues was the same as that described above for wild-type fly tissues. The controls for the wild-type were adults from a per ${ }^{01} ; r y^{506}$ strain.

For all three strains, at least 50 flies were examined by whole-mount procedures (Liu et al., 1991) and more than 10 sectioned and examined by electron microscopy.

Confocal microscopy. The per- $\beta$-gal fusion gene transgenic strain has been described previously. The fusion protein contains the $\mathrm{N}$-terminal 630 amino acids of PER (Liu et al., 1988). The immunohistochemical procedures were as previously described (Liu et al., 1988), except that two primary antibodies were used simultaneously. The anti- $\beta$-gal antibody (Cappel) was followed by a biotinylated secondary antibody (Vector Laboratories) and then by streptavidin-Texas red (Molecular Probe Inc.). The anti-nuclear antibody 8C5 (Fujita et al., 1982) was followed by an FITC-conjugated secondary antibody (Cappel). Tissues were analyzed with a confocal scanning laser microscope (Bio-Rad MRC 500). Image processing was performed with software provided by the manufacturer.

\section{Results}

In initial experiments, tissues from adult wild-type fly heads were stained with an anti-PER peptide antibody (Siwicki et al., 1988) and examined in the EM, but the signal was not sufficient for EM analysis. As the light microscopic signal from a per- $\beta$ gal fusion gene was more intense but otherwise very similar to that of wild-type PER (Liu et al., 1988; Siwicki et al., 1988), we then carried out a series of EM experiments by staining adult tissues from this strain with anti- $\beta$-gal antibodies. The negative control was a per ${ }^{01} ; r y^{506}$ double mutant (the latter an cyc color marker) that was the host strain for the transformations (Liu et al., 1988). We also used a more recent anti-PER antibody, generated against almost the entire coding sequence expressed in bacteria (see Materials and Methods). This antibody has been previously used for light microscopy (Liu et al., 1991), and it stains PER more strongly but otherwise indistinguishably from the anti-peptide antibody (Siwicki et al., 1988). Consequently, we carried out a series of EM experiments by staining adult tissues from wild-type flies with this new reagent. The negative control for expression in wild-type was the per ${ }^{01}$ mutant, which is arrhythmic and has a stop codon in the per gene's fourth exon (Baylies et al., 1987; Yu et al., 1987). As previously described for the anti-peptide antibody (Siwicki et al., 1988), only very weak background staining was observed in the perol strain (Liu et al., 1991). The background staining in the per strain is indistinguishable from that obscrved in a per-deletion strain (B. Frisch, unpublished observations), indicating that a major fraction of the antibody activity is directed downstream of this stop codon or that the per ${ }^{01}$ nonsense fragment is relatively unstable (see below). To avoid redundant descriptions, only some of the 

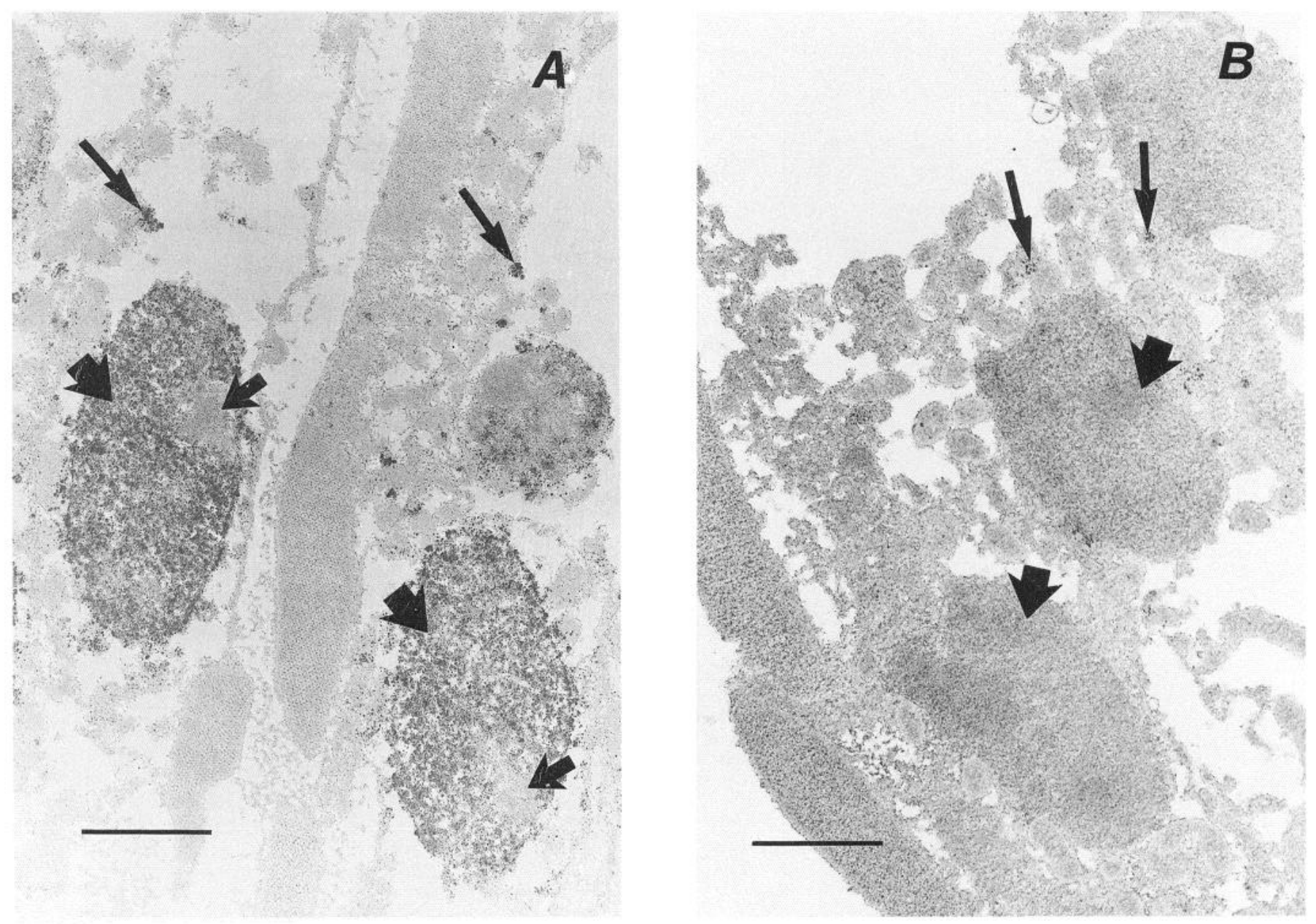

Figure 1. Transmission electron micrographs (TEMs) of thin sections from the compound eye of wild-type $(A)$ and per $(B)$ flies stained with anti-PER antibody. In $A$, the short, thick arrows point to the nuclei of the photoreceptor cells (R1-R6), the short, thin arrows to the putative nucleoli, and the long, thin arrows to signals in the cytoplasm of these photoreceptor cells. In $B$, the short arrows point to the signal-free nuclei of the photoreceptor cells (R1-R6), and the long arrows to "nonspecific" signals in the cytoplasm of these mutant photoreceptor cells. Scale bars, $2 \mu \mathrm{m}$.

results from the transformant strain will be presented, mostly for cases in which they were different from those from a wildtype strain.

Eye

The compound eyes of Drosophila are composed of photoreceptor cells (R1-R8), pigment cells, and cone cells (Miller, 1965b). By light microscopy, per expression was restricted to the photoreceptor cells (Liu et al., 1988; Saez and Young, 1988; Siwicki et al., 1988; Zerr et al., 1990). In the EM, PER antigen was prominent in the nuclei of these cells (Fig. 1A, short, thick arrows). The antigen-free region inside of the nucleus (Fig. 1A, short, thin arrows) is likely the nucleolus. There were some cytoplasmic signals (Fig. 1A, long, thin arrows), but similar, perhaps less intense signals were also seen in the control (Fig. $1 B$, long arrows). The results from the per- $\beta$-gal transformant flies were very similar (data not shown). The nuclear region of the negative controls (Fig. 1 $B$, short arrows; and data not shown) was essentially signal free.

\section{Brain}

The adult fly brain consists of two major regions, the optic lobes and the central brain (Miller, 1965a; Kankel et al., 1980). per expression in the central brain is probably sufficient for rhythmic behavior, although normal optic lobe morphology may be required for a robust wild-type phenotype (Handler and Konopka, 1979; Helfrich and Engelmann, 1983; Konopka et al., 1983; Helfrich, 1986; Dushay et al., 1989). The per gene is expressed in many small cells distributed throughout these two regions of the anterior CNS (Liu et al., 1988; Saez and Young, 1988; Siwicki et al., 1988). It is also expressed in some apparently larger cells in the central brain, among which the most prominent are the so-called "lateral neurons" located in a cortical region on each side of the head (Siwicki et al., 1988; Zerr et al., 1990; Liu et al., 1991).

In the EM, most of optic lobe cells are small, about $2 \mu \mathrm{m}$ in diameter, with little cytoplasm (Power, 1943) (Fig. 2A). Antigen was located in a low percentage of the cells in these lobes (conservatively estimated at less than $1 \%$ ) and was nuclear in every case (Fig. $2 B, C$ ). These positive optic lobe cells appeared to fall into two groups. One contained relatively small cells with very little cytoplasm; they were usually located at the boundary of the cortex and neuropil regions (Fig. $2 B$ ). It is possible that these are glial cells, as previously suggested (Siwicki et al., 1988). In this group, no signal was detected outside of the nuclei. Cells in the other group were marginally larger with somewhat more 
Figure 2. TEMs of thin sections from the optic lobes of wild-type, per ${ }^{\circ 1}$, and $p e r-\beta$-gal fusion gene transgenic flies. $A$, The cortex region (top) and the neuropil region (bottom) of part of the optic lobes (medulla) from a wild-type fly head without treatment with immunoreagents. $B-E$, The same region as in $A$, but from wild-type $(B, C)$, per ${ }^{11}(D)$, and per- $\beta$-gal fusion gene transgenic $(E)$ heads, following staining with anti-PER antibody $(B-D)$ or anti- $\beta$-gal antibody $(E)$. In $C$, the large and small arrows point to the nuclear and cytoplasmic regions, respectively. The arrowheads in both $B$ and $C$ point to the cell membrane. In $E$, the arrow points to the nucleus. Scale bars, $2 \mu \mathrm{m}$.
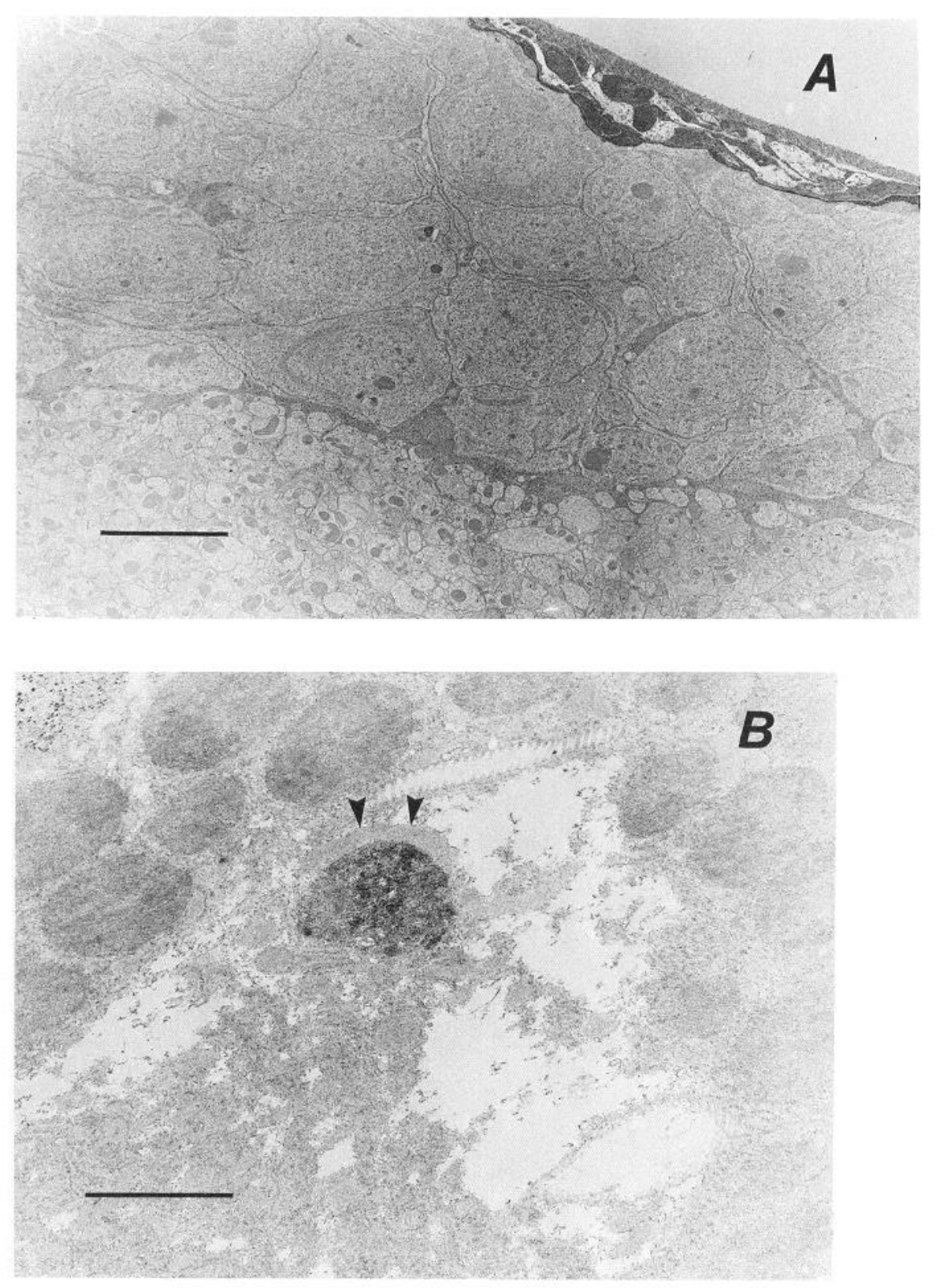

cytoplasm and were found at all locations within the optic lobe cortex. Although most of the signal in these cells was also nuclear (Fig. $2 C$, large arrow), there was some signal in the limited cytoplasmic region (Fig. $2 C$, small arrow). As expected (Siwicki et al., 1988; Liu et al., 1991), no immunohistochemical signal was detected in the optic lobes of per ${ }^{01}$ flies (Fig. 2D).

In the central brain cortex region, we also observed very few per-positive cells (data not shown), similar to the positive optic lobe cells described above. Because our previous light microscopic experiments had visualized some relatively large positive cells, we also looked for such cells at the EM level. We concentrated on the lateral central brain cortex region that contains the previously described lateral neurons (Siwicki et al., 1988). In this region, larger cells (with both larger nuclei and more cytoplasm than the cells described above) are intermingled with smaller ones (Power, 1943) (Fig. 3A). In one experiment, we examined 1500 sections and observed antigen in these large brain cells, and most of the per antigen was nuclear (Fig. $3 B$, large solid arrow). The subnuclear region without signal is almost certainly the nucleolus (Fig. $3 B$, open arrow), yet there was also a substantial amount of per antigen associated with the cytoplasm (Fig. $3 B$, small solid arrow). We did not see any signal in the central brain of per ${ }^{11}$ control flies (Fig. 3C).

Immunolocalization of brain staining from the transformant flies was, in the main, consistent with that from wild-type flies. In most brain locations, we detected a low percentage of small cells with prominent nuclear staining (e.g., Fig. $2 E$, arrow). There were, however, two differences with the results from the wildtype flies. First, the putative lateral neurons described above were not detected in the transformant flies. Second, and in addition to the expected nuclear staining, we detected a weak signal in the cytoplasmic region of putative laminar (optic lobe) epithelial glial cells (Trujillo-Cenoz, 1965; Saint Marie and Carlson, $1983 a, b)$. Cytoplasmic staining with anti- $\beta$-gal antibodies (or 

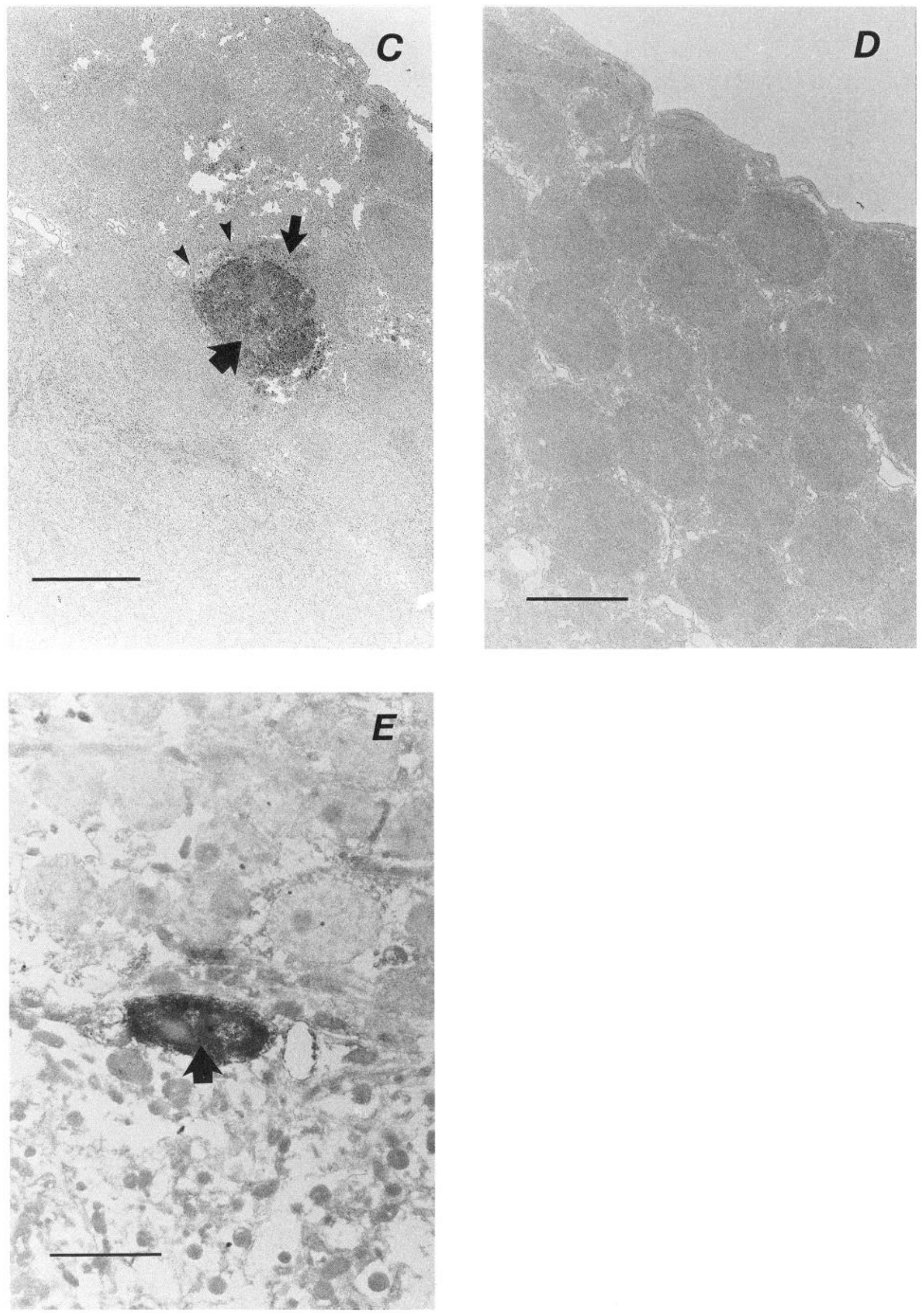

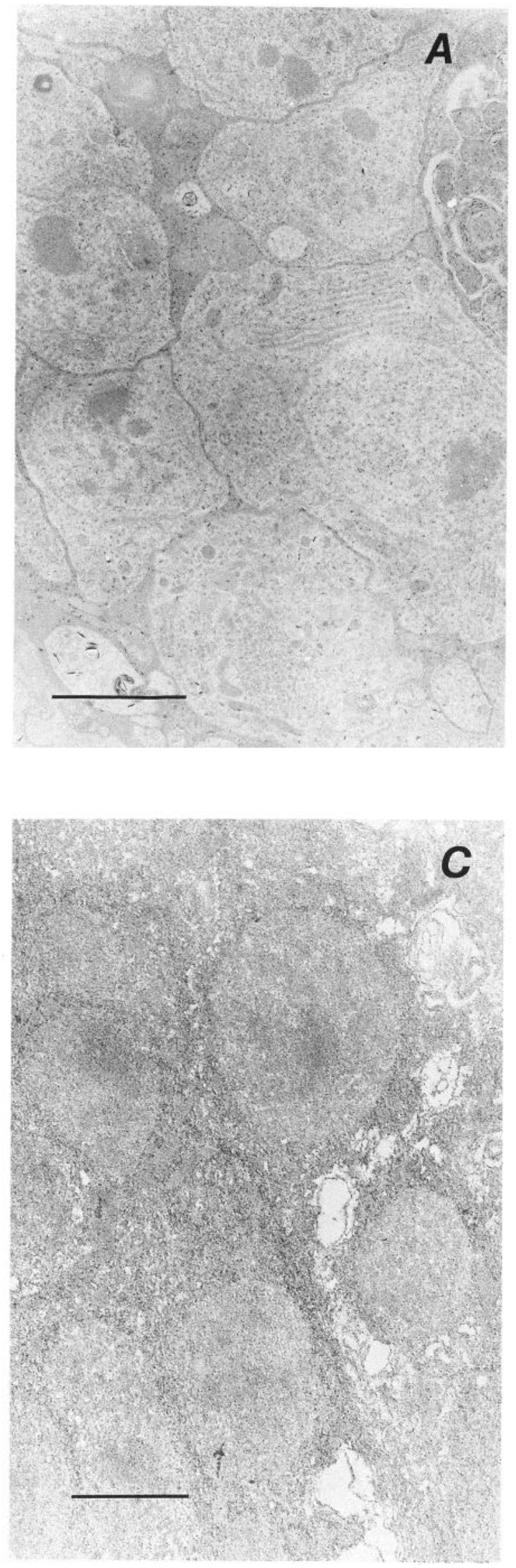

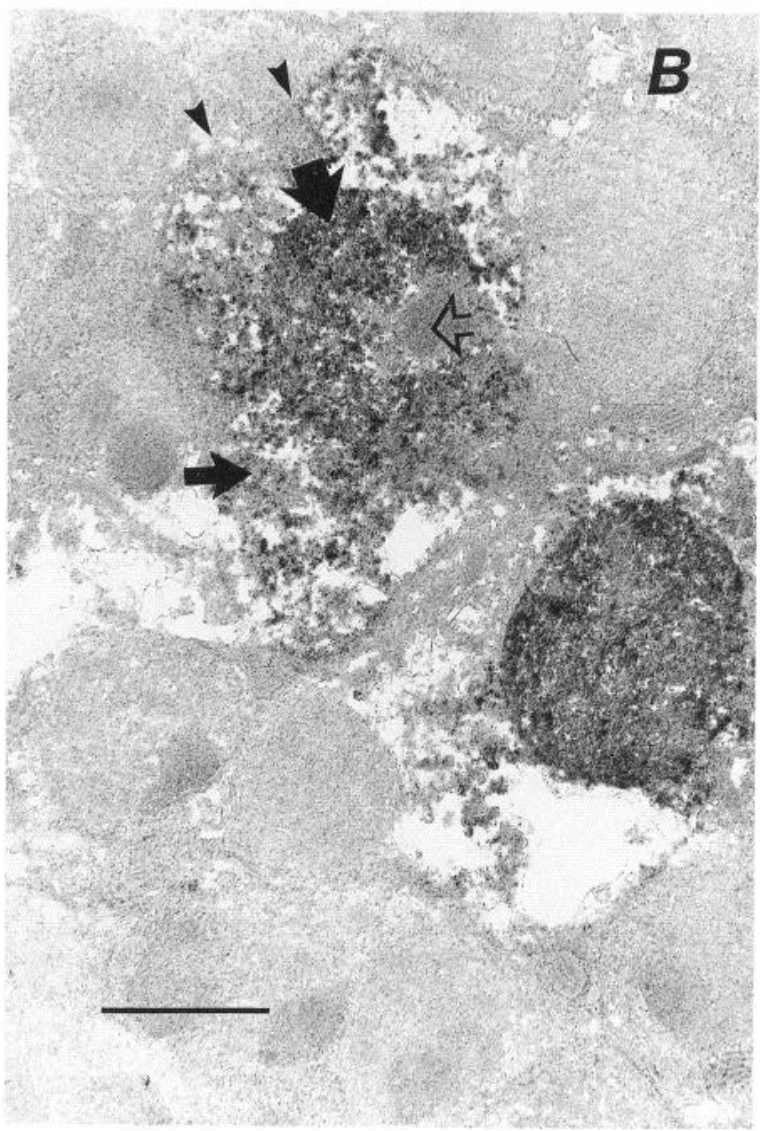

Figure 3. TEMs of thin sections from the central brain region of wildtype and per ${ }^{01}$ flies. $A$, The cortex region of part of the lateral central brain from a wild-type head without the immunohistochemical procedure. $B$ and $C$, Anti-PER antibody staining of a region similar to that shown in $A$, but from wild-type $(B)$ and $p^{\circ}{ }^{11}(C)$ fly heads. In $B$, the large and small solid arrows point to the nuclear and cytoplasmic regions, respectively; the arrowheads point to cell membrane; and the open arrow points to a putative nucleolar region. Scale bars, $2 \mu \mathrm{m}$. 


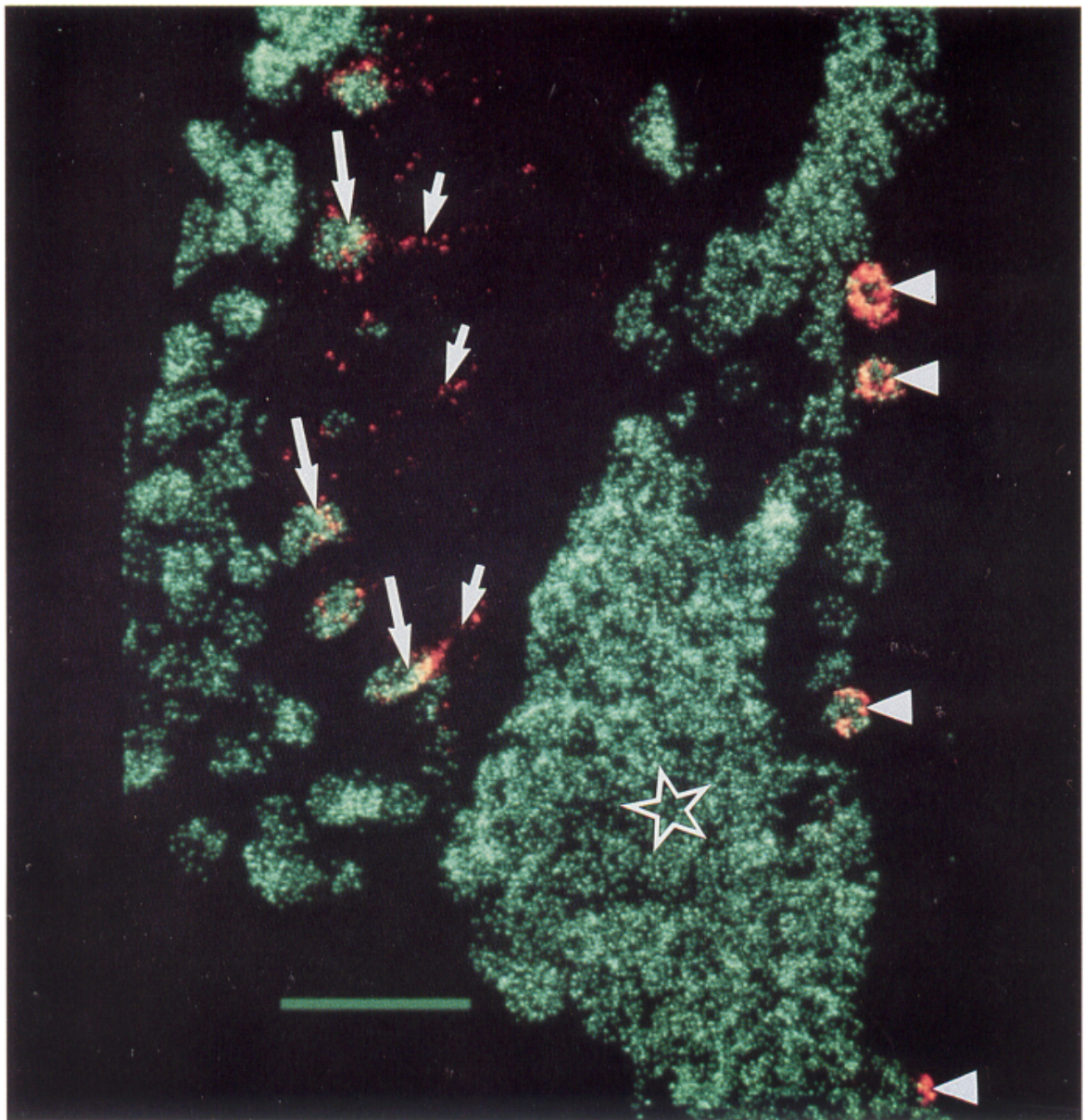

Figure 4. Double-staining confocal microscopy of frozen sections through the head of a per- $\beta$-gal fusion gene transformant. The long and short arrows point to the putative laminar epithelial glial cells' nuclei and cytoplasm, respectively. The arrowheads point to the double-stained nuclei of cells between the cortex and neuropil regions of the medulla. The starindicates a ganglionic cortex region. $\beta$-Gal staining is red, nuclear staining is green, and double-stained nuclei are yellow. Scale bar, $10 \mu \mathrm{m}$.
$\mathrm{X}$-gal) had been previously observed in the light microscopic experiments (Liu et al., 1988) and was also visible by doublestaining confocal microscopy (Fig. 4). The green staining was due to the antibody $8 \mathrm{C} 5$, a monoclonal reagent that stains the nuclei of all cell types in Drosophila (Fujita et al., 1982). The red staining was due to the anti- $\beta$-gal antibody. When these two patterns were superimposed, the costaining locations were yellow (Fig. 4, arrowheads and long arrows). In addition, there was red staining in the cytoplasmic regions of these epithelial glial cells (Fig. 4, short arrows). As described above, note that only a low percentage of the medulla cells (Fig. 4, star) are $\beta$-gal positive; that is, compare the four double-staining nuclei in the medulla (Fig. 4, arrowheads) to the large number of medulla nuclei (Fig. 4, green stain around the star).

\section{Non-neural tissues}

In both gut and Malpighian tubules, PER was mostly located in the nucleus (Fig. $5 A, B$, solid arrows). The antigen was not evenly distributed in these large nuclei (Fig. $5 B$, arrowheads). The signal-free regions were likely nucleoli (Fig. 5B, open arrow). Results from the fusion gene transformants were once again very similar to those from wild-type flies (data not shown). In ovaries of wild-type flies, per expression had been previously detected at low resolution both by in situ hybridization (Liu et al., 1988) and by antibody staining [in the latter case with an independently generated anti-PER antibody (Saez and Young, 1988)], yet in the EM, there was no signal above the level observed in the negative control per ${ }^{01}$ flies (data not shown). per- $\beta$-gal fusion protein expression had been detected by light microscopy in ovarian follicle cells of the transformant strain (Liu et al., 1988), and a clear cytoplasmic signal was detected in these cells by EM (Fig. 6, arrows). This signal was absent in the negative control strain (data not shown). We presume that PER is not present at sufficiently high concentration in wild-type follicle cells to be visible either by light microscopy (Siwicki et al., 1988) or by EM. The follicle cells of these transformant females are the only cells or tissue where PER (or in this case the per- $\beta$ gal fusion protein) appears to be predominantly cytoplasmic.

\section{Discussion}

The experiments reported here extend the per gene spatial expression pattern in adult Drosophila to the subcellular level. Detection of PER antigen in the EM required a "strong" polyclonal antibody as well as substantial calibration of the histochemical techniques (see Materials and Methods). For all of the positive cells in the nervous system that we encountered, nuclei were the principal subcellular compartment with signal; in no case did signal in the cytoplasm predominate. Neither the nuclear nor the cytoplasmic signal was associated with any recognizable structure, due perhaps to the loss of fine structure during the antibody staining procedure. This was due in large part to the mild fixation procedures and prolonged incubation time required to retain antigenicity for both PER and $\beta$-galactosidase and to detect them. Yet there was never detectable signal associated with the cell membranes (Figs. $2 B, C ; 3 B$; arrowheads), nor did we see signal associated with neurite pro- 

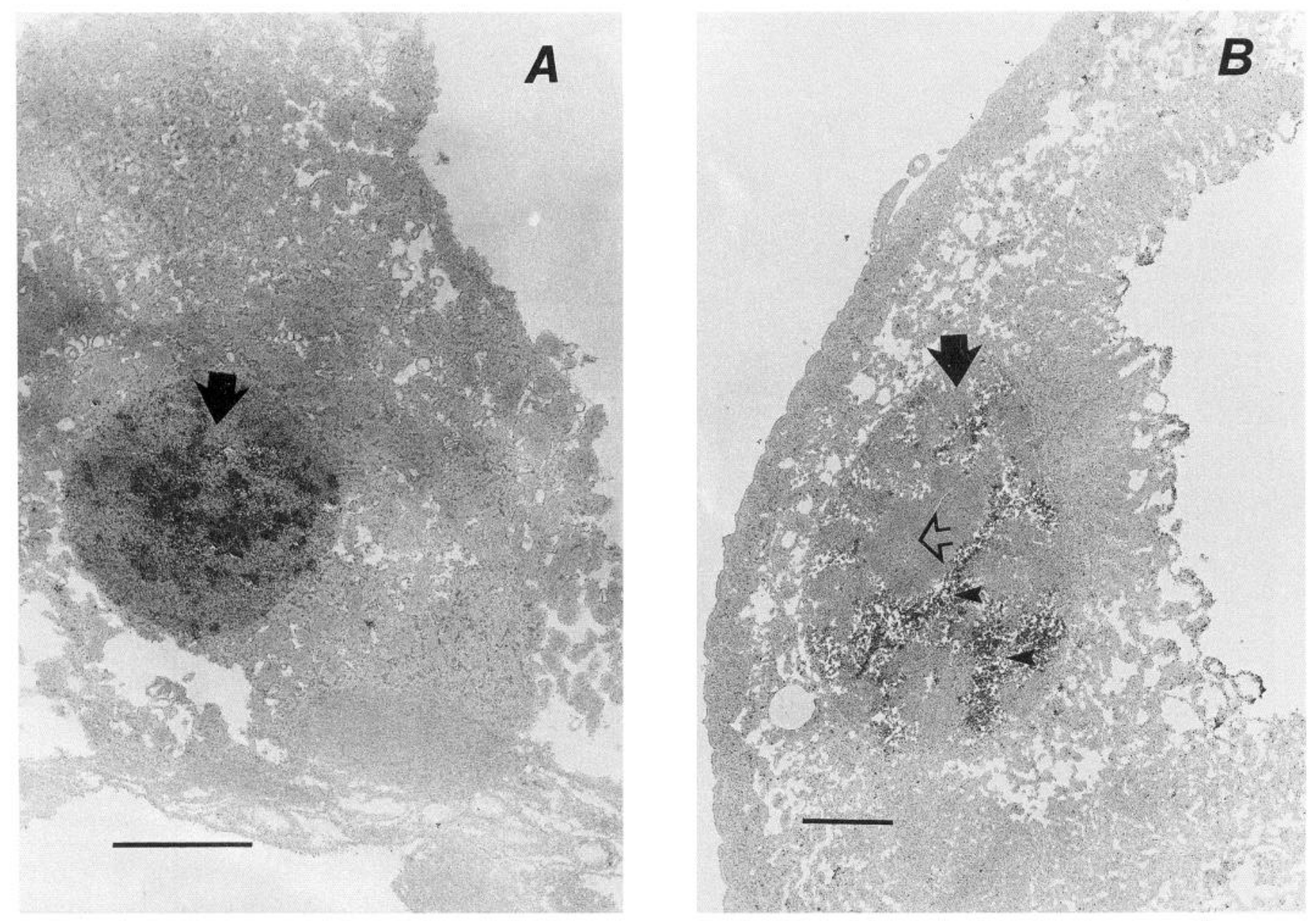

Figure 5. TEMs of thin sections from the gut $(A)$ and the Malpighian tubules $(B)$ of wild-type flies stained with anti-PER antibody. In $A$, the arrow points to the nucleus of an epithelial cell in the midgut. In $B$, the solid arrow points to the nucleus of an epithelial cell of the Malpighian tubule, arrowheads point to a signal-rich region of the nucleus, and the open arrow points to the putative nucleolus. Scale bars, $2 \mu \mathrm{m}$.

cesses in brain neuropil regions (e.g., bottom of Fig. 2C). Also, in no case did we observe signals in adults that resembled the reported "cell boundary" staining in larval salivary glands (Bargiello et al., 1987). Whereas it is possible that this difference reflects heterogeneity of subcellular locations in different tissues, we have never been able to visualize convincingly per expression in developing salivary glands. It is important to note that this failure does not depend on a single antibody preparation, but it is also true for in situ hybridization with nucleic acid probes and for the expression of a per- $\beta$-galactosidase fusion gene, which otherwise faithfully reproduce the expression pattern observed with direct antibody staining (James et al., 1986; Liu et al., 1988; Siwicki et al., 1988). In larval salivary glands, per's expression levels as well as subcellular localization may be exceptional (Bargiello et al., 1987), reflecting perhaps an unusual function for PER in this tissue.

The conclusion that PER is principally an intranuclear protein clarifies previous light microscopic observations of per protein, or per- $\beta$-gal fusion protein, within brain cells. Antibody staining was difficult to assign definitively to a single subcellular compartment and was described as apparently nuclear, perinuclear, and cytoplasmic (Liu et al., 1988; Saez and Young, 1988; Siwicki et al., 1988). The data presented here indicate that the previous interpretations were probably due to the small size of many of the positive cells, a prominent signal-free nucleolus, and in some cases a non-negligible level of cytoplasmic signal. We cannot, however, exclude the possibility that the large cells visualized in the EM do not correspond to the lateral neurons described previously (Siwicki et al., 1988).

The cellular and subcellular locations of the per- $\beta$-gal fusion gene product were very similar to those of the PER antigen. This correspondence indicates that in general the portion of the per polypeptide in the fusion protein [the N-terminal half of the per protein (Liu et al., 1988)] retains sufficient information to direct the fusion protein to the nucleus and that the $\beta$-gal moiety does not interfere with this process. There were, however, a few exceptions in which the PER pattern and the per- $\beta$-gal pattern were different. First, the fusion protein was detected in the cytoplasm as well as in the nucleus of small lamina cells (putative epithelial glial cells). It could be that some of the fusion protein is misdirected in this tissue. A similar conclusion was reached in other spatial localization studies involving $\beta$-gal fusion systems (Mismer and Rubin, 1987; Fortini and Rubin, 1990). Second, the fusion protein was detected in the cytoplasm of ovarian follicle cells. Although per gene expression in follicle cells had been previously described, PER was not visible in this tissue (from wild-type females), due perhaps to the decreased detection sensitivity of PER as compared to the fusion gene product. As 


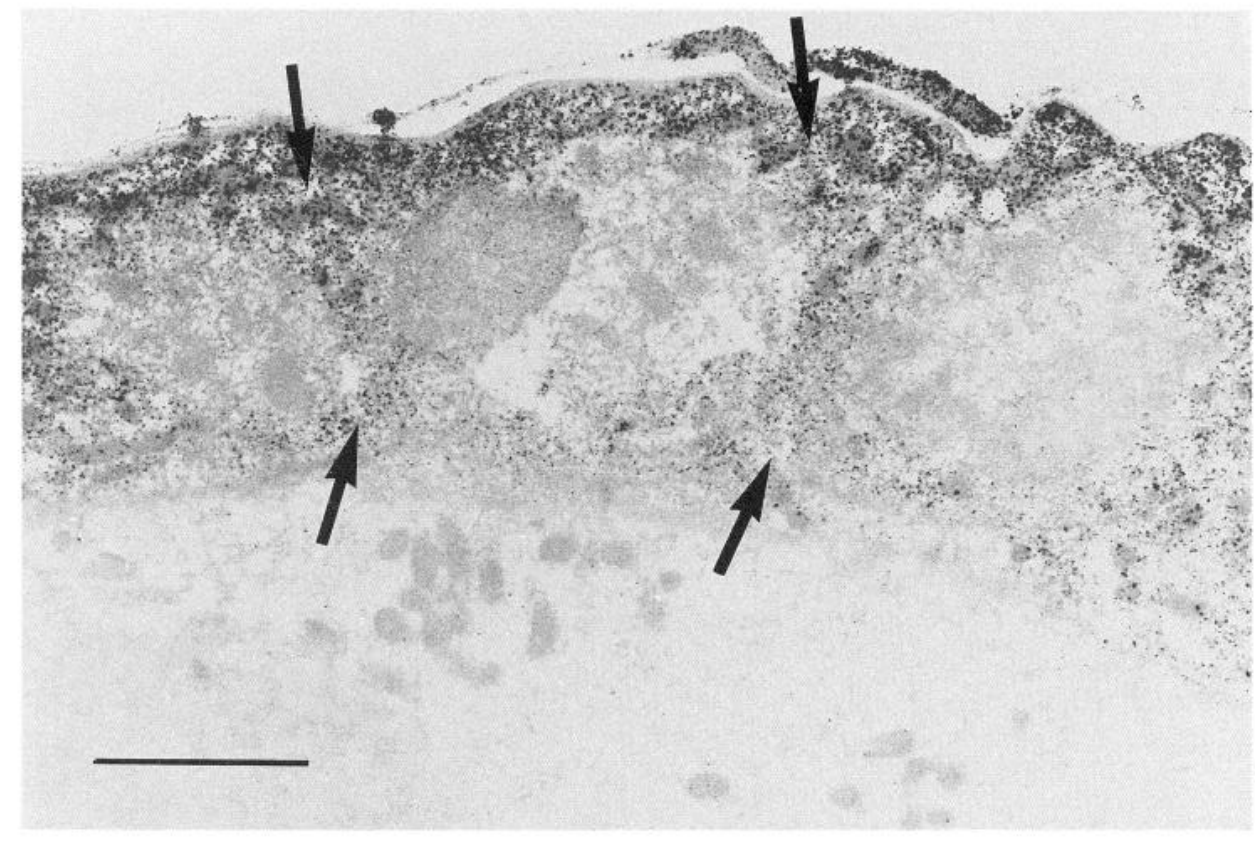

Figure 6. TEM of thin section from the ovary of a per- $\beta$-gal fusion gene transformed female stained with anti$\beta$-gal antibody. Arrows point to the signals in the cytoplasm of the follicle cells surrounding the immature egg chambers. In this region, signals have also been observed at low resolution in this transformant (Liu et al., 1988). Scale bar, $2 \mu \mathrm{m}$.

a consequence, we do not know whether PER is also predominantly cytoplasmic in this tissue or whether the fusion protein is inappropriately targeted. Third, cells with the expected characteristics of the lateral neurons were not identified in the brain of the transformant flies. As these were difficult to find by EM in wild-type fly brains (see above), this difference is probably not significant.

The relatively uniform picture of PER localization within brain cells now points to the nucleus as the primary compartment within which it exercises its influence on circadian rhythms. In this regard, it is of interest to consider per's two known relatives. One is the Drosophila single-minded gene ( $\operatorname{sim})$, which shares with per a statistically significant $\sim 200$ amino acid sequence motif (Crews et al., 1988). Although $\operatorname{sim}$ protein (SIM) has not been examined at the EM level, it appears to be a nuclear protein in the embryonic CNS and is suspected to be involved in controlling the expression of other "neural genes" (Crews et al., 1988; Nambu et al., 1990, 1991; Klambt et al., 1991). The other per relative is the human aryl hydrocarbon receptor nuclear translocator (ARNT), which also contains the sequence motif shared between SIM and PER (Hoffman et al., 1991). Present in both ARNT and SIM is a basic-helix-loop-helix motif characteristic of many transcription factors (Davis et al., 1987; Villares and Cabrera, 1987; Caudy et al., 1988; Murre et al., 1989; Hoffman et al., 1991; S. Crews, personal communication). Interestingly, the ARNT protein is a subunit of an aryl hydrocarbon receptor complex that moves from the cytoplasm to the nucleus and is important for the transcription of specific genes in response to ligand (Fujisawa-Sehara et al., 1987; Denison et al., 1988; Hapgood et al., 1989; Hoffman et al., 1991).

Although the sequence motif shared by PER, SIM, and ARNT has had no specific function assigned to it, this conservation, the suspected role of SIM and ARNT in transcription, and the PER subcellular localization reported here lead to the speculation that PER's function in the brain is to affect transcription. This could be correlated with the presence of PER in both nuclear and cytoplasmic compartments, given that other transcription factors are so localized (Picard and Yamamoto, 1987;
Lenardo and Baltimore, 1989; Roth et al., 1989; Steward, 1989; Hoffman et al., 1991). Taken together with our previous observations that PER influences the circadian fluctuations of its own mRNA (Hardin et al., 1990; Zwiebel et al., 1991), we suggest that PER acts at the transcriptional level to affect these fluctuations and to regulate other downstream "clock-controlled genes" (cf. Loros et al., 1989; Loros and Dunlap, 1991; Kay and Millar, in press). The circadian oscillator would then include per and perhaps other components of the transcriptional machinery.

\section{References}

Bargiello TA, Saez L, Baylies MK, Gasic G, Young MW, Spray DC (1987) The Drosophila clock gene per affects intercellular junctional communication. Nature 328:686-691.

Baylies MK, Bargiello TA, Jackson FR, Young MW (1987) Changes in abundance and structure of the per gene product can alter periodicity of the Drosophila clock. Nature 326:390-392.

Caudy M, Vassin H, Brand M, Tuma R, Jan LY, Jan YN (1988) Daughterless, a Drosophila gene essential for both neurogenesis and sex determination, has sequence similarities to myc and the achaetescute complex. Cell 55:1061-1067.

Citri Y, Colot HV, Jacquier AC, Yu Q, Hall JC, Baltimore D, Rosbash $M$ (1987) A family of unusually spliced biologically active transcripts encoded by a Drosophila clock gene. Nature 326:42-47.

Crews ST, Thomas JB, Goodman CS (1988) The Drosophila singleminded gene encodes a nuclear protein with sequence similarity to the per gene product. Cell 52:143-152.

Davis RL, Weintraub H, Lassar AB (1987) Expression of a single transfected cDNA converts fibroblasts to myoblasts. Cell 51:9871000.

Denison M, Fisher JM, Whitlock JP Jr (1988) Inducible, receptordependent protein-DNA interactions at a dioxin-responsive transcriptional enhancer. Proc Natl Acad Sci USA 85:2528-2532.

Dushay MS, Rosbash M, Hall JC (1989) The disconnected visual system mutations in Drosophila melanogaster drastically disrupt circadian rhythms. J Biol Rhythms 4:1-27.

Ewer J, Rosbash M, Hall JC (1988) An inducible promoter fused to the period gene in Drosophila conditionally rescues adult per-mutant arrhythmicity. Nature 333:82-84.

Ewer J, Hamblen-Coyle M, Rosbash M, Hall JC (1990) Requirement for period gene expression in the adult and not during development 
for locomotor activity rhythms of imaginal Drosophila melanogaster. J Neurogenet 7:31-73.

Fortini ME, Rubin GM (1990) Analysis of cis-acting requirements of the Rh 3 and Rh4 genes reveals a bipartite organization to rhodopsin promoters in Drosophila melanogaster. Genes Dev 4:444-463.

Fujisawa-Sehara A, Sogawa K, Yamane M, Fujii-Kuriyama Y (1987) Characterization of xenobiotic responsive elements upstream from the drug-metabolizing cytochrome $P 450 \mathrm{c}$ gene: a similarity to glucocorticoid regulatory elements. Nucleic Acids Res 15:4179-4186.

Fujita SC, Zipursky SL, Benzer S, Ferrus A, Shotwell SL (1982) Monoclonal antibodies against the Drosophila nervous system. Proc Natl Acad Sci USA 79:7929-7933.

Hall JC, Rosbash M (1988) Mutations and molecules influencing biological rhythms. Annu Rev Neurosci 11:373-393.

Handler AM, Konopka RJ (1979) Transplantation of a circadian pacemaker in Drosophila. Nature 279:236-238.

Hapgood J, Cuthill S, Denis M, Poellinger L, Gustafsson J (1989) Specific protein-DNA interactions at a xenobiotic-responsive element: copurification of dioxin receptor and DNA binding activity. Proc Natl Acad Sci USA 86:60-64.

Hardin PE, Hall JC, Rosbash M (1990) Feedback of the Drosophila period gene product on circadian cycling of its messenger RNA levels. Nature 343:536-540.

Harlow E, Lane D (1988) Antibodies: a laboratory manual. Cold Spring Harbor, NY: Cold Spring Harbor Laboratory.

Helfrich C (1986) Role of the optic lobes in the regulation of the locomotor activity rhythm of Drosophila melanogaster: behavioral analysis of neural mutants. J Neurogenet 3:321-343.

Helfrich C, Engelmann W (1983) Circadian rhythm of the locomotor activity in Drosophila melanogaster mutants 'sine oculis' and 'small optic lobes'. Physiol Entomol 8:257-272.

Hoffman EC, Reyes H, Chu F, Sander F, Conley LH, Brooks BA, Hankinson O (1991) Cloning of a factor required for activity of the Ah (dioxin) receptor. Science 252:954-958.

Jackson RF, Bargiello TA, Yun S-H, Young MW (1986) Product of the per locus of Drosophila shares homology with proteoglycans. Nature 320:185-188.

James AA, Ewer J, Reddy P, Hall JC, Rosbash M (1986) Embryonic expression of the period clock gene in the central nervous system of Drosophila melanogaster. EMBO J 5:2313-2320.

Kankel DR, Ferrus A, Garen SH, Harte PJ, Lewis PE (1980) The structure and development of the nervous system. In: The genetics and biology of Drosophila (Ashburner M, Wright TRF, eds), pp 295368. New York: Academic.

Kay SA, Millar AJ (1992) Circadian regulated $c a b$ gene transcription in higher plants. In: Molecular biology of circadian rhythms (Young $M W$, ed), in press.

Klambt C, Jacobs JR, Goodman C (1991) The midline of the Drosophila central nervous system: a model for the genetic analysis of cell fatc, cell migration, and growth cone guidance. Cell 64:801-815.

Konopka R, Wells S, Lee T (1983) Mosaic analysis of a Drosophila clock mutant. Mol Gen Genet 190:284-288.

Konopka RJ, Benzer S (1971) Clock mutants of Drosophila melanogaster. Proc Natl Acad Sci USA 68:2112-2116.

Lenardo MJ, Baltimore D (1989) NF-kB: a pleiotropic mediator of inducible and tissue-specific gene control. Cell 58:227-229.

Liposits Z, Setalo G, Flerko B (1984) Application of silver-gold intensified 3,3'-diaminobenzidine chromogen to the light and electron microscopic detection of the luteinizing hormone-releasing hormone system of rat brain. Neuroscience 13:513-525.

Liu X, Lorenz L, Yu Q, Hall JC, Rosbash M (1988) Spatial and temporal expression of the period gene in Drosophila melanogaster. Genes Dev 2:228-238.

Liu X, Yu Q, Huang Z, Zwiebel LJ, Hall JC, Rosbash M (1991) The strength and periodicity of Drosophila melanogaster circadian rhythms are differentially affected by alterations in period gene expression. Neuron 6:753-766.

Loros JJ, Dunlap JC (1991) Neurospora clock-controlled genes are regulated at the level of transcription. Cell Biol 11:558-563.
Loros JJ, Denome SA, Dunlap JC (1989) Molecular cloning of genes under control of the circadian clock in Neurospora. Science 243:385388.

Miller A (1965a) The central nervous system. In: Biology of Drosophila (Demerec M, ed), pp 483-495. New York: Hafner.

Miller A (1965b) The sense organs. In: Biology of Drosophila (Demerec M, ed), pp 498-507. New York: Hafner.

Mismer D, Rubin GM (1987) Analysis of the promoter of the ninaE opsin gene in Drosophila melanogaster. Genetics 116:565-578.

Murre C, McCae PS, Baltimore D (1989) A new DNA binding and dimerization motif in immunoglobulin enhancer binding, daughterless, MyoD, and $m y c$ proteins. Cell 56:777-783.

Nambu JR, Franks RG, Hu S, Crews ST (1990) The single-minded gene of Drosophila is required for the expression of genes important for the development of CNS midline cells. Cell 63:63-75.

Nambu JR, Lewis JO, Wharton KA, Crews ST (1991) The Drosophila single-minded gene encodes a helix-loop-helix protein that acts as a master regulator of CNS midline development. Cell 67:1157-1167.

Picard D, Yamamoto KR (1987) Two signals mediate hormone-dependent nuclear localization of the glucocorticoid receptor. EMBO J 6:3333-3340.

Power ME (1943) The brain of Drosophila melanogaster. J Morphol 72:517-559.

Rosbash M, Hall JC (1989) The molecular biology of circadian rhythms. Neuron 3:387-398.

Rosenberg AH, Lade BN, Chui D-s, Lin S-W, Dunn JJ, Studier FW (1986) Vectors for selective expression of cloned DNAs by T7 RNA polymerase. Gene 56:125-135.

Roth S, Stein D, Nüsslein-Volhard C (1989) A gradient of nuclear localization of the dorsal protein determines dorsoventral pattern in the Drosophila embryo. Cell 59:1189-1202.

Saez L, Young MW (1988) In situ localization of the per clock protein during development of Drosophila melanogaster. Mol Cell Biol 8: 5378-5385.

Saint Marie RL, Carlson SD (1983a) The fine structure of neuroglia in the lamina ganglionaris of the housefly, Musca domestica L. J Neurocytol 12:213-241.

Saint Marie RL, Carlson SD (1983b) Glial membrane specializations and the compartmentalization of the lamina ganglionaris of the housefly compound eye. J Neurocytol 12:243-275.

Siwicki KK, Eastman C, Petersen G, Rosbash M, Hall JC (1988) Antibodies to the period gene product of Drosophila reveal diverse tissue distribution and rhythmic changes in the visual system. Neuron 1: 141-150.

Steward R (1989) Relocalization of the dorsal protein from the cytoplasm to the nucleus correlates with its function. Cell 59:11791188

Studier FW, Moffatt BA (1986) Use of bacteriophage T7 RNA polymerase to direct selective high-level expression of cloned genes. J Mol Biol 189:113-130.

Trujillo-Cenoz O (1965) Some aspects of the structural organization of the intermediate retina of dipterans. J Ultrastruct Res 13:1-33.

Villares R, Cabrera CV (1987) The achaete-scute gene complex of D. melanogaster: conserved domains in a subset of genes required for neurogenesis and their homology to myc. Cell 50:415-424.

Young MW, Bargiello TA, Baylies MK, Saez L, Spray DC (1989) Molecular biology of the Drosophila clock. New York: Dekker.

Yu Q, Jacquier AC, Citri Y, Hamblen M, Hall JC, Rosbash M (1987) Molecular mapping of point mutations in the period gene that stop or speed up biological clocks in Drosophila melanogaster. Proc Natl Acad Sci USA 84:784-788.

Zerr DM, Rosbash M, Hall JC, Siwicki KK (1990) Circadian fluctuations of period protein immunoreactivity in the CNS and the visual system of Drosophila. J Neurosci 10:2749-2762.

Zwiebel LJ, Hardin PE, Liu X, Hall JC, Rosbash M (1991) A posttranscriptional mechanism contributes to circadian cycling of per- $\beta$ galactosidase fusion protein. Proc Natl Acad Sci USA 88:3882-3886. 